\title{
Success Factors for Using Case Method in Teaching Applied Data Science Education
}

\author{
Valentina Chkoniya \\ GOVCOPP, ISCA-UA, University of Aveiro, Portugal
}

\begin{abstract}
In a world where everything involves data, an application of it became essential to the decision-making process. The Case Method approach is necessary for Data Science education to expose students to real scenarios that challenge them to develop the appropriate skills to deal with practical problems by providing solutions for different activities. Data science combines multiple fields like statistics, scientific methods, and data analysis to extract value from data, being an umbrella term used for multiple industries, such as data analytics, data mining, machine learning, big data, business intelligence, and predictive analytics. This paper gives an overview of success factors for using the Case Method in teaching Applied Data Science education. Showing that close analysis provides a deeper understanding of implications, connects theory to practice, and classes unfold without a detailed script when successful instructors simultaneously manage content and process. This synthesis of current research can be used by Applied Data Science educators to more effectively plan the use of the Case Method as one possible teaching method.
\end{abstract}

Keywords: data science, education, marketing intelligence, case method, learning methodology

\section{Introduction}

Data science (DS) is about decision-making in an increasingly data-driven world we live in today. It has employed great efforts in developing advanced analytics, improving data models, and cultivating new algorithms. However, there are organizational and socio-technical challenges that arise when executing a DS project: lack of vision and clear objectives, a biased emphasis on technical issues, a low level of maturity for ad-hoc projects, and the ambiguity of roles in DS are among these challenges (Chkoniya et al., 2020; Martinez et al., 2021).

As companies power up model development, DS teams are going into overdrive to better connect and communicate with business leaders. Firms are launching data literacy programs to help business teams better understand what DS is and what it can do (Babcock, 2020).

Demand for DS education is surging and traditional teaching methods are not meeting the needs of those seeking training. In a data-driven society, the main priority is to bring applications to the forefront. The individuals tasked with developing DS courses should not only have statistical and computing training but also have experience analyzing data with the main objective of solving real-world problems (Hicks \& Irizarry, 2018). 
This paper gives an overview of the contribution of Case Method (CM) teaching to applied DS education.

\section{Background}

DS is a new profession emerging along with the exponential growth in the era of digital overexposure. A data scientist provides support to the decision-making process by looking at past and current data. Application of it is an essential skillset in a world of uncertainty where everything from communication to transport, industry to commerce, involves data.

In this section, an overview of possible contributions of CM teaching to respond to challenges of applied DS education. Showing that, unlike lectures, applied DS education cannot happen only in passive reception of knowledge classroom isolation, it requires a deeper understanding of implications in real cases. Through their close analysis, the CM connects theory to practice, and classes unfold without a detailed script when successful instructors simultaneously manage content and process. Applied DS and CM Teaching definitions used for the analysis in this review are introduced.

\section{Case Method}

Case Learning (Wang \& Yang, 2010) and Case Study approach (Garg \& Varma, 2007) are among two other synonymous terms by which CM is also known (Razali \& Zainal, 2013).

Teaching based on cases or problems can be traced back to Christopher Columbus Langdell, who prepared the first casebook for students in the Harvard Law School in the 1870s (ServantMiklos, 2019). This method was adapted to business education by Edwin Gay, the first dean of the Harvard Business School, in 1908 (Lima \& Fabiani, 2014). Since then, the method has spread into curricula in many fields (Lundberg \& Winn, 2005). The CM is a Socratic studentled system where students review a case (a story about how an organization faced a specific business problem) and have to think through possible solutions and what they would do in the same situation (Stoten, 2020). Critical thinking is "the ability to make decisions based on data, with its inherent uncertainties and variability" (Holmes et al., 2015). Unlike other teaching methods, there is no lecturing with the CM (Patil \& Karadesai, 2016).

\section{Data science}

Data Science (DS) is inherently applied and interdisciplinary, it is a unique blend of skills from analytics, engineering \& communication aiming at generating value from the data itself (Braschler et al., 2019). DS combines multiple fields including statistics, scientific methods, and data analysis to extract value from data, being is an umbrella term used for multiple industries, such as data analytics, big data, business intelligence, data mining, machine learning and artificial intelligence, and predictive analytics, and is being increasingly adopted to analyze and predict consumer behavior (Chkoniya, 2020; Cognetik, 2020).

Where:

Big data is a collection of unstructured data that has a very large volume. The major demanding issues in big data processing include storage, search, distribution, transfer, analysis, and visualization (Khade, 2016). 
Data mining is defined as a process used to extract usable data from a larger set of raw data. It implies analyzing data patterns in large batches of data using one or more software (Ge et al., 2017).

Predictive analytics is the branch of advanced analytics which is used to make predictions about unknown future events (Kumar et al., 2020).

Machine Learning is used in DS to make predictions and also to discover patterns in the data, in situations where necessary the machine learn from the big amounts of data, and then apply that knowledge to new pieces of data that streams into the system (Liu et al., 2018; Zolghadri \& Couffin, 2018).

Artificial Intelligence is the field of study that describes the capability of Machine Learning just like humans and the ability and refers to programs, algorithms, systems, and machines that demonstrate intelligence (Khanna et al., 2020; Shankar, 2018).

Business intelligence is a data analysis process that organizations use to gain insights into business performance and improve operational decision-making (Jakhar \& Krishna, 2020).

\section{Methodology}

To better understand challenges in decoding consumer behavior with DS, this paper presents a systematic literature review that helps to understand the contribution of CM Teaching to Applied DS Education.

One way to achieve greater rigor and better levels of reliability in a literature review is to adopt a systematic approach, which allows the researcher to make a rigorous and reliable assessment of the research carried out within a specific topic (Levy \& Ellis, 2006). The result must be the "state of the art" and demonstrate that the research in question contributes something new to the existing body of knowledge, the methodological approach is mainly supported in three phases: input; processing, and output (Sampaio, 2007). The input phase begins with the definition and presentation of the main goal of this research: "Determine the most recent applications of DS techniques in CBR context".

After that, continues with the process of data source identification requiring the definition of rigorous string that suits the different bibliographic databases selected. Scientific articles (ar) or conference proceedings (cp) related to CBR and DS from six main academic databases were searched. These academic databases include Springer Link, Web of Science, Scopus, IEEE Explore, Google Scholar, and Science Direct. Concerning the goal of identify the publications related to research works around the application of CM Teaching in DS, in the first, it is used the string: TITLE-ABS-KEY ("CM Teaching") AND TITLE-ABS-KEY ("DS") AND (LIMIT-TO (DOCTYPE, "cp") OR LIMIT-TO (DOCTYPE, "ar")). So, applying exclusion and inclusion criteria cited, the total document results are 821 . In this case, as all results are about recent articles, published between 2017 and 2021, in the English language.

All the publications titles and abstracts were read manually for relevance checking. This process resulted in 79 publications being excluded. Lastly, 21 eligible publications were selected. The analyzed publications were investigated based on the relevance to the research domain and availability. 


\section{Findings and Discussion}

While DS is somewhat a "hot topic" there is still little literature that addresses the applied side of DS.

Emerging technologies like the DS are bringing new opportunities, challenges, and solutions for many domains including agriculture, plant sciences, animal sciences, food sciences, and social sciences. These disruptive technologies are at the center of the fourth industrial revolution, but we not ready yet to educate and prepare new generations to help society, science, and humanity adapt them (Catal \& Tekinerdogan, 2019).

\section{Case Method as the Potential Solution}

It has been long argued that social science education must transform itself to support students' acquisition of twenty-first-century competencies, such as critical thinking, effective communication, and collaborative problem-solving. Recognizing the limitations of the lecture model in fostering these competencies, scholars favor to integrate theory with practice. There are three most common approaches currently used to introduce practice in the business curriculum: the CM, internships, and problem-based learning with four building blocks of a management learning epistemology (Perusso \& Baaken, 2020):

Ill-defined problems where students.

Execute solutions in real-life.

In close collaboration with a real organization, with learning.

Supported by a process of reflection (Perusso \& Baaken, 2020).

In the context of applied DS education, the action-oriented goals for decision-making literacy education often demand a more active, situated approach to instruction. A key philosophical model that can meet these needs is experiential learning. Field-based, hands-on experiential learning is a mainstay of meaningful science education throughout a student's career (O'Neil et al., 2020). Drawn from the work of Dewey, Lewin, Piaget, and others, this philosophy views learning as a dialectical process that integrates concrete, personal experiences with reflection, consideration, and application (O'Neil et al., 2020; Warren, 1995; Wilson \& Beard, 2013). Experiential learning is distinguished from traditional approaches in that learning constitutes a process - where "concepts are derived from and continuously modified by experience" (Kolb \& Kolb, 2017) - rather than the accumulation of a fixed set of ideas or outcomes.

CMs, or case-based learning, like other problem-based methods, are intended to develop students' ability to solve problems using knowledge, concepts, and skills relevant to a course. Cases provide contextualized learning, as contrasted with learning disassociated from meaningful contexts. The CM has long been used effectively in business and law education (McKeachie et al., 2006; Razali \& Zainal, 2013). Its potential use in Applied Science such as Applied DS however has yet to be further explored.

\section{How Harvard's case method can help bridge the gap between DS and decision making}

The discipline of DS has emerged over the past decade as a convergence of high-power computing, data visualization and analysis, and data-driven application domains. Prominent research institutions and private sector industries have embraced DS, but foundations for effective tertiary-level DS education remain absent (Turek et al., 2016). 
There are three foundation stones for DS projects success: project, team, and data \& information management. This is a constantly evolving and improving framework to adapt to new challenges in DS, generating uncertainty (Martinez et al., 2021).

Harvard Business School Professor C. Roland Christensen was the world's leading authority on CM teaching, which he described as "the art of managing uncertainty" (Barnes et al., 1994; Cullen, 2013; Forman \& Rymer, 1999).

In $\mathrm{CM}$, subjects are presented to students through real cases whereby students themselves either individually or in group discussions work through the problems and issues presented in the cases (Razali \& Zainal, 2013). The CM approach is deemed necessary for DS education to expose students to real scenarios that challenge them to develop the appropriate skills to deal with practical problems. As a largely theoretical subject, DS students could understand more about the practical application of DS concepts and ideas via such active learning activities.

Case developers usually equip the cases with a teaching note (Erskine et al., 2019) that guides instructors on how to deliver the materials, for instance, highlighting important issues and providing sample questions. In exploring solutions in a case discussion, students place themselves in the shoes of the protagonists and try to analyze the issues that drive the decision-making process (Hoffer, 2020).

Case-based learning provides opportunities to increase engagement and foster inclusion for diverse communities of learners. Teaching with cases leverages the strengths of storytelling to help students internalize abstract concepts. Stories are the way we make sense of the world and translate abstract concepts into understanding. CM has a focus on engagement and inclusion, spanning traditional educational settings, online learning, and one-to-one virtual coaching models. Findings of research studies that assess case-based learning outcomes are provided, along with suggestions for incorporating new material into existing curricula to help learners construct new understandings and build inclusive behavior skills (Hoffer, 2020).

This indirectly trains students to confront real issues and to develop experience in proposing practical solutions. The basic criteria for a good case include: a clear problem statement; focus on one issue or problem; and alignment with the program objectives. Besides, cases must be based on meaningful realistic situations, which do not contain ideal and clear-cut solutions (Zhang \& Li, 2010). The rationale behind having no clear-cut solutions is that the answers finally offered should come from students' deep analysis, discussion, and understanding, rather than being self-evident. This facilitates students in enhancing their analytical and problem-solving skills as well as promoting proactive learning (Razali \& Zainal, 2013).

The results indicate that four main factors contribute to the acceptance of CM among students as a method for teaching and learning. The factors are Environment, Case, Instructor, and Student. Each factor has its own constituted criteria or characteristics that determine the efficacy of the method (Razali \& Zainal, 2013).

\section{Success Factors}

Successful experiential learning occurs when students take initiative and actively participate in there. Further, experiential learning is augmented when disciplinary content is applied in authentic contexts and can therefore be 'tested' against relevant real-world problems with opportunities for reflection and refinement (Knobloch, 2003; O’Neil et al., 2020). 
Demand for DS education is surging and traditional courses offered by statistics departments are not meeting the needs of those seeking training (Hicks \& Irizarry, 2018). The American Statistical Association (ASA) has recognized changes in training made necessary by a changing landscape. In 2005, they first put out suggestions for a direction for the future of introductory statistics, and they updated these suggestions again in 2016 (Carver et al., 2016). Their target is teaching introductory statistics at a college, but the wisdom contained also applies to teaching DS in any environment:

Teach statistical thinking.

Focus on conceptual understanding.

Integrate real data with a context and purpose.

Foster active learning.

Use technology to explore concepts and analyze data.

Use assessments to improve and evaluate student learning.

The increasing use of CM in teaching and research ushered in a paradigm shift in pedagogical approach in recent years. It underscores the relevance of traditional learning discourses in professional education. Cases focus primarily on the individual development, cognitive behavior, personality, learning, interaction pattern and examine the interplay of all variables (Tripathy, 2009).

For example, there has been a great deal of recent educational research pointing out the significant measurable benefits of active learning (Koedinger et al., 2015; Wieman, 2014). It's also worth pointing out that some scholars argue that these suggestions point in the right direction but are simply not enough (Cobb, 2015).

Austin, Heskett, and Bartlett surveyed their colleagues at the Harvard Business School and determined eight characteristics of excellent cases (Austin et al., 2015):

Focus - important issue(s), requiring a plan or action

Completeness - sufficient narrative and data to answer the questions

Clarity and Succinctness - targeted and organized detail

Engagement - enable identification with stakeholders

Controversy - richness of conflict and issues

Complexity - layered dilemmas lacking obvious solutions

Robustness - requiring analysis, rigor, supported assumptions 8. Intellectual Richness opportunity for insights and discovery

Building an environment in which students feel free to expose their knowledge state and compassionately help each other learn is incredibly difficult. The idea of a growth mindset was first put forth by Carol Dweck (2017). Their research points out the importance of students believing that they can improve through practice. More interestingly, perhaps, they offer suggestions as to how to foster growth mindsets such as praising effort as opposed to skill (Hicks \& Irizarry, 2018). 


\section{Conclusions}

Demand for data science education is surging and traditional courses offered by statistics departments are not meeting the needs of those seeking training (Hicks \& Irizarry, 2018). Cases can help students grasp concepts, develop skills, become more engaged, and satisfied in the learning process. Also, cases can help faculty develop more inclusive learning environments. In line with the Kolb (2017) framework for experiential learning, a case or a story can provide an experience that engages students to reflect, to build a revised understanding of the world by applying new concepts, and to test this understanding in new situations. While navigating this cycle, faculty have the opportunity to introduce concepts of diversity and inclusion (Hoffer, 2020).

In an Applied Data Science course, the CM can help students gain the perspective of new decision-makers. Building upon findings, future studies can address the effects of CM implementation in practice.

This synthesis of current research can be useful to teachers and the student community by providing evidence about the contribution of case learning methodology in applied data science education.

\section{References}

[1] Austin, J., Heskett, J., \& Bartlett, C. (2015). Key Elements for Excellence in Classroom Cases and Teaching Notes. Harvard Business School Background Note.

[2] Babcock, K. (2020). How Harvard's case method can help bridge the gap between Business and Data Science. Domino, (Perspective). Retrieved from https://www.dominodatalab.com/blog/how-harvards-case-method-can-helpbridge-the-gap-between-business-and-data-science/

[3] Barnes, L. B., Barnes, L. B., Christensen, C. R., Barnes, P. L. B., Hansen, A. J., \& Hansen, T. L. (1994). Teaching and the Case Method: Text, Cases, and Readings. Harvard Business School Press. Retrieved from https://books.google.pt/books?id=32UK0OiZrskC

[4] Braschler, M., Stadelmann, T., \& Stockinger, K. (2019). Applied data science : lessons learned for the data-driven business. Applied data science lessons learned for the data-driven business. Cham, Switzerland: Springer. https://doi.org/10.1007/9783-030-11821-1

[5] Carver, R., Everson, M., Gabrosek, J., Horton, N. J., Lock, R., Mocko, M., ... Wood, B. (2016). Guidelines for Assessment and Instruction in Statistics Education (GAISE) College Report 2016.

[6] Catal, C., \& Tekinerdogan, B. (2019). Aligning Education for the Life Sciences Domain to Support Digitalization and Industry 4.0. Procedia Computer Science, 158, 99-106. https://doi.org/10.1016/j.procs.2019.09.032

[7] Chkoniya, V. (2020). Challenges in Decoding Consumer Behavior with Data Science. European Journal of Economics and Business Studies, 3, 77-87.

[8] Chkoniya, V., Madsen, A. O., \& Bukhrashvili, P. (2020). Anthropological Approaches to Understanding Consumption Patterns and Consumer Behavior. Hershey, PA, USA: IGI Global. https://doi.org/10.4018/978-1-7998-3115-0 
[9] Cobb, G. (2015). Mere Renovation is Too Little Too Late: We Need to Rethink our Undergraduate Curriculum from the Ground Up. The American Statistician, 69(4), 266-282. https://doi.org/10.1080/00031305.2015.1093029

[10] Cognetik. (2020). Leveraging Data Science to Understand User Behavior. Digital Marketing. Retrieved from https://contentsquare.com/blog/leveraging-datascience-to-understand-user-behavior/

[11] Cullen, A. (2013). Using the Case Method to Introduce Information Skill Development in the MBA Curriculum. Journal of Business \& Finance Librarianship, 18(3), 208-232. https://doi.org/10.1080/08963568.2013.795740

[12] Dweck, C. S. (2017). Summary of Carol S. Dweck's Mindset: Key Takeaways \& Analysis. CreateSpace Independent Publishing Platform.

[13] Erskine, J., Leenders, M., \& Mauffette-Leenders, L. (2019). Teaching with Cases, 3rd Edition / Learning with Cases, 5th Edition (Book Set) (5th ed.). Ontario: Ivey Publishing.

[14] Forman, J., \& Rymer, J. (1999). The Genre System of the Harvard Case Method. Journal of Business \& Technical Communication, 13(4), 373-400. https://doi.org/10.1177/105065199901300401

[15] Garg, K., \& Varma, V. (2007). A Study of the Effectiveness of Case Study Approach in Software Engineering Education. In 20th Conference on Software Engineering Education Training (CSEET'07) (pp. 309-316). https://doi.org/10.1109/CSEET.2007.8

[16] Ge, Z., Song, Z., Ding, S. X., \& Huang, B. (2017). Data Mining and Analytics in the Process Industry: The Role of Machine Learning. IEEE Access, 5, 20590-20616. https://doi.org/10.1109/ACCESS.2017.2756872

[17] Hicks, S. C., \& Irizarry, R. A. (2018). A Guide to Teaching Data Science. The American Statistician, 72(4), 382-391. https://doi.org/10.1080/00031305.2017.1356747

[18] Hoffer, E. R. (2020). Case-Based Teaching: Using Stories for Engagement and Inclusion. International Journal on Social and Education Sciences, 2(2), 75-80.

[19] Holmes, N. G., Wieman, C. E., \& Bonn, D. A. (2015). Teaching critical thinking. Proceedings of the National Academy of Sciences, 112(36), 11199-11204. https://doi.org/10.1073/pnas.1505329112

[20] Jakhar, R., \& Krishna, C. (2020). Business Intelligence: As a Strategic Tool for Organization Development (A Literature Review). ANWESH: International Journal of Management \& Information Technology, 5(1), 44-46.

[21] Khade, A. A. (2016). Performing Customer Behavior Analysis using Big Data Analytics. Procedia Computer Science, 79, 986-992.

https://doi.org/https://doi.org/10.1016/j.procs.2016.03.125

[22] Khanna, V., Ahuja, R., \& Popli, H. (2020). ROLE OF ARTIFICIAL INTELLIGENCE IN PHARMACEUTICAL MARKETING: A COMPREHENSIVE REVIEW. Journal of Advanced Scientific Research, 11(3), 54-61.

[23] Knobloch, N. A. (2003). Is Experiential Learning Authentic. Journal of Agricultural Education, 44, 22-34.

[24] Koedinger, K. R., Kim, J., Jia, J. Z., McLaughlin, E. A., \& Bier, N. L. (2015). Learning is Not a Spectator Sport: Doing is Better than Watching for Learning from a MOOC. In Proceedings of the Second (2015) ACM Conference on Learning @ Scale (pp. 111120). New York, NY, USA: Association for Computing Machinery.

https://doi.org/10.1145/2724660.2724681 
[25] Kolb, D., \& Kolb, A. (2017). The Experiential Educator: Principles and Practices of Experiential Learning.

[26] Kumar, A., Singh, S. S., Singh, K., \& Biswas, B. (2020). Link prediction techniques, applications, and performance: A survey. Physica A: Statistical Mechanics and Its Applications, 553. https://doi.org/10.1016/j.physa.2020.124289

[27] Levy, Y., \& Ellis, T. (2006). A Systems Approach to Conduct an Effective Literature Review in Support of Information Systems Research. International Journal of an Emerging Transdiscipline, 9. https://doi.org/10.28945/479

[28] Lima, M., \& Fabiani, T. (2014). Teaching with cases, a framework based approach.

[29] Liu, Q., Feng, G., Wang, N., \& Tayi, G. K. (2018). A multi-objective model for discovering high-quality knowledge based on data quality and prior knowledge. Information Systems Frontiers, 20(2), 401-416. https://doi.org/10.1007/s10796016-9690-6

[30] Lundberg, C. C., \& Winn, J. (2005). The Great Case- Teaching-Notes Debate. Journal of Management Education, 29(2), 268-283. https://doi.org/10.1177/1052562904264284

[31] Martinez, I., Viles, E., \& G. Olaizola, I. (2021). Data Science Methodologies: Current Challenges and Future Approaches. Big Data Research, 24. https://doi.org/10.1016/j.bdr.2020.100183

[32] McKeachie, W. J., Svinicki, M., Svinicki, M. D., Hofer, B. K., \& Suinn, R. M. (2006). McKeachie's Teaching Tips: Strategies, Research, and Theory for College and University Teachers. Houghton Mifflin. Retrieved from https://books.google.pt/books?id=oMDuAAAAMAAJ

[33] O’Neil, J. M., Newton, R. J., Bone, E. K., Birney, L. B., Green, A. E., Merrick, B., ... Fraioli, A. (2020). Using urban harbors for experiential, environmental literacy: Case studies of New York and Chesapeake Bay. Regional Studies in Marine Science, 33. https://doi.org/10.1016/j.rsma.2019.100886

[34] Patil, M. J., \& Karadesai, S. G. (2016). To Determine the Effectiveness of Case Based Tutorials As Compared To Traditional Tutorials in Microbiology. National Journal of Integrated Research in Medicine, 7(2), 5-8.

[35] Perusso, A., \& Baaken, T. (2020). Assessing the authenticity of cases, internships and problem-based learning as managerial learning experiences: Concepts, methods and lessons for practice. The International Journal of Management Education, 18(3). https://doi.org/10.1016/j.ijme.2020.100425

[36] Razali, R., \& Zainal, D. A. P. (2013). Success Factors for Using Case Method in Teaching and Learning Software Engineering. International Education Studies, 6(6), 191-201.

[37] Sampaio, R. (2007). Estudos de revisão sistemática: Um guia para síntese criteriosa da evidência científica. Revista Brasileira De Fisioterapia - REV BRAS FISIOTER, 11. https://doi.org/10.1590/S1413-35552007000100013

[38] Servant-Miklos, V. F. C. (2019). The Harvard Connection: How the Case Method Spawned Problem-Based Learning at McMaster University. Health Professions Education, 5(3), 163-171. https://doi.org/https://doi.org/10.1016/j.hpe.2018.07.004

[39] Shankar, V. (2018). How Artificial Intelligence (AI) is Reshaping Retailing. Journal of Retailing, 94(4), vi-xi. https://doi.org/https://doi.org/10.1016/S00224359(18)30076-9 
[40] Stoten, D. W. (2020). Practical Heutagogy: Promoting Personalized Learning in Management Education. Adult Learning, 31(4), 161-174.

https://doi.org/10.1177/1045159520905364

[41] Tripathy, M. R. (2009). Case Methodology in Teaching \& Research: A Critical Review. Indian Journal of Industrial Relations, 44(4), 660-671.

[42] Turek, D., Suen, A., \& Clark, D. (2016). A Project-Based Case Study of Data Science Education. Data Sci. J., 15, 5.

[43] Wang, Z., \& Yang, C. (2010). Research on Case Learning System for Engineering Subject - Software Engineering as an Example. In 2010 10th IEEE International Conference on Computer and Information Technology (pp. 2101-2104). https://doi.org/10.1109/CIT.2010.357

[44] Warren, K. (1995). The Theory of Experiential Education. A collection of articles addressing the historical, philosophical, social, and psychological foundations of Experiential Education. ERIC.

[45] Wieman, C. E. (2014). Large-scale comparison of science teaching methods sends clear message. Proceedings of the National Academy of Sciences of the United States of America, 111(23), 8319-8320.

[46] Wilson, J. P., \& Beard, C. (2013). Experiential learning: A handbook for education, training and coaching. Kogan Page Publishers.

[47] Zhang, J., \& Li, J. (2010). Teaching Software Engineering Using Case Study. https://doi.org/10.1109/ICBECS.2010.5462378

[48] Zolghadri, M., \& Couffin, F. (2018). One-off or batch upgrading of complex products and systems: concepts, data model and analysis framework. Research in Engineering Design, 29(2), 263-284. https://doi.org/10.1007/s00163-017-0268-1 